\title{
Erratum to: Human Immune Monitoring Techniques during Food Allergen Immunotherapy
}

Blake J. Rust ${ }^{1}$ - Erik Wambre ${ }^{1}$

Published online: 20 September 2017

(C) Springer Science+Business Media, LLC 2017

Erratum to: Curr Allergy Asthma Rep (2017) 17: 22

DOI 10.1007/s11882-017-0689-y

In the original version of this article the first author's name was listed as Blake Rust. It should have read Blake J. Rust. The correct author name is given above.

The online version of the original article can be found at http://doi.org/10. 1007/s11882-017-0689-y

Erik Wambre

ewambre@benaroyaresearch.org

1 Department of Translational Immunology, Benaroya Research Institute, Seattle, WA, USA 